or the general practitioner who treats practically all wounds with the freest of applications of iodine and dry dressings.

Only the other day I was speaking to a surgeon on the staff of one of our greatest hospitals. I asked him how wounds were treated in the casualty department-was it with iodine and dry dressings? "That's it," he said. "What then," said I, "if 2 per cent. iodine is only a germicide like 1 in 50 carbolic?" "Oh," he answered, "that would be an awful pity, because we have all pinned our faith to it so." There is the whole point. Have we been right or wrong in pinning our faith to it so?

If wrong, so far as I am concerned, I do not want to hunt for this, that, or the other vaunted remedy. I shall go back to phenol pure for the wound and 1 in 20 for the surrounding parts. But I confess if we are wrong I shall be disappointed. Iodine is so quick in application, so simple, and, strange to say, so successful. Nevertheless, if it is established that its use is unsafe because of its feeble antiseptic powers, let us do away with it, because, as I have tried to show, its use has become "the method of choice" with so many. It should be for them now to establish or otherwise its effectiveness.

I am, Sir, yours faithfully,

ALexander Brown, M.B. Lond.

London, N.W., Dec. 19th, 1914.

\section{HYALINE CASTS IN THE URINE.}

\section{To the Editor of THE LANCET.}

SIR,-The interesting annotation in your issue of Dec. 26th last on the origin and nature of granular and hyaline renal casts leads me to think it worth while to ask the question, "What is the value of hyaline casts in the urine as an indication of renal disease, or even of renal disturbance?" After many years' observation I can say that they are to be found so often in the sediment of the centrifugalised urine, without any other evidence of renal disease, that they may often be passed by as of no moment, and I even venture to doubt if many of them come from the kidney at all. If there be no other evidence of renal disturbance they may, I think, be neglected. Surely they cannot all be washed out blood casts. Might not many of them be mucinous, and added to the urine in transit, and, if so, how distinguish between those of renal origin and those that are extraneous?

I am, Sir, yours faithfully,

Dec. 26th, 1914

JAMES F. GOODHART.

\section{A MINISTRY OF PUBLIC HEALTH.}

\section{To the Editor of THE LANCET.}

SIR,-The leading article in THE IAANCET of Dec. 19th, 1914, on the necessity for a Ministry of Public Health will be welcomed by many inter. ested in public health. At the present time matters relating to public health are the concern of at least three different bodies-viz., the Board of Education, the Local Government Board, with its Public Health and Poor-law Departments, and the National Health Insurance Commission. That overlapping of the duties of these various bodies, considerable as it is, does not take place to a greater extent must be the result of the earnest desire for coöperation and coördination on the part of the chief medical officials responsible for the work of the several bodies. It would seem obvious that to coördinate the work of these several bodies another body, the Ministry of Public Health, should be instituted.

The present crisis has accentuated in the minds of the public the extreme importance of the health of the nation. Whether the individual rely in the future for the maintenance of our place among nations on force of arms or efficiency in manufacture or trade, all are at one on the necessity for the physical fitness of the inhabitants of the Empire. When peace is restored the attention of the public will be fixed in an increased degree on the measures necessary to obtain this result. The scope of the work of medical officers engaged in public health duties will be increased and a high degree of efficiency demanded.

But the present conditions as regard training, appointment, and service do not make for efficiency. The rapid headway made by the present movement for the improvement of the status of the medical officers actually engaged in the work of medical inspection of school children is a proof, if any were wanted, of the need for overhauling the whole system and the formation of a Public Health Service on the lines of the Naval, Military, and Indian Medical Services, with due regard to the principles of local government. This duty can only be under. taken by a Ministry of Public Health.

I am, Sir, yours faithfully,

Brighton, Dec. 21st, 1914. C. W. Hutw.

\section{VACCINES AND THE GERMAN RAID : A USEFUL ANALOGY. \\ To the Editor of THE LANCET.}

SIR,-The recent raid on the Yorkshire coast seems to provide so good an analogy to the action of vaccines on the human body that it may serve to clarify our ideas on the indications and contraindications for vaccine treatment. The Germans obviously play the part of the germs which have invaded the body, while leucocytes are fairly comparable with the soldiers of the invaded country.

Let us consider the Yorkshire coast as the site of the injection of a vaccine into England. Here, as elsewhere, the young men, specially of the rural districts, have shown symptoms of lethargy and have not converted themselves into leucocytes as freely as they might have done. (I take the liberty of alternating the metaphor freely.) The injection of toxins by battleships into the superficial English tissues in Yorkshire will certainly result in a marked local leucocytosis, and these leucocytes will join the general blood stream and increase the general resisting powers of the body. If not the immunisation machinery of the body is in a very unhealthy state.

Again, when an efficient dose of vaccine is injected under the skin a red, angry lump is quickly formed at the site of injection consisting of leucocytes and antibodies antagonising the injected toxins. Doubtless we shall soon see some such local response in the case of our coast towns, taking the form of local levies or guns. But this raid illustrates also what $I$ feel to be a further action of a vaccine-viz., that the injection of a proper dose of bacterial toxins acts as a circulating signal to rouse the defences of the whole body to a sense of the reality of invasion. And this is generally 